\title{
Inovasi Kegiatan Masa Kini Perpustakaan Kafe Literacy Coffee
}

\author{
${ }^{1}$ Nur`aini, ${ }^{2}$ Duarta Sitanggang, ${ }^{3}$ Afryna Veronica, ${ }^{4}$ Aulia Rahma \\ Ritonga \\ 1234 Universitas Sumatera Utara \\ 1E-mail: nuraini@usu.ac.id
}

\begin{abstract}
The Cafe Library is a library designed with coffee shops and books. The cafe library provides more value to visitors and provides a place of comfort for visitors who come so they don't feel bored to the library. The cafe library can be used as an innovative alternative as a place for recreation/educational tourism. One of the functions of the library is a place of recreation for the community. Libraries are required to play an active, innovative and creative role to make the visitors who come can feel happy and satisfied. The layout of the space needs to be considered in order to increase the role of the library as a place of recreation and a vehicle for education for the wider community. To make the library a place of recreation and a vehicle for education for visitors/communities who come, it is necessary to have innovations carried out in the form of activities or services made by library managers. The purpose of this study is to find out the innovations of contemporary activities carried out by the literacy coffee cafe library. This research takes place in the literacy coffee cafe library. This study uses a qualitative method with a descriptive approach. Data collection techniques were carried out by means of observation, interviews, and documentation. Data reduction, data presentation and conclusion/data verification are data analysis of this research. The results of this study show that literacy coffee cafe library managers develop innovative activities for visitors/communities who come. Various innovative activities carried out in the literacy coffee cafe library such as general discussions, political discussions, book reviews, film reviews, and film classes. This research is expected to be a reference for other cafe libraries to develop or improve innovative activities so that visitors/communities feel at home visiting literacy coffee.
\end{abstract}

Keywords: Cafe Library; Coffee Literacy Activities; Cafe Library Innovation.

\author{
Abstrak \\ Tik Ilmeu : Jurnal Ilmu Perpustakaan dan Informasi \\ IAIN Curup | p-issn: 2580-3654; e-issn:2580-3662
}

DOI: $10.29240 /$ tik.v5i2.3127 
Perpustakaan Kafe merupakan perpustakaan yang didesain dengan warung kopi dan buku. Perpustakaan kafe memberikan nilai lebih kepada pengunjung dan memberikan tempat kenyamanan kepada pengunjung yang datang agar tidak merasa bosan ke perpustakaan. Perpustakaan kafe dapat dijadikan alternatif yang inovatif sebagai tempat rekreasi/wisata pendidikan. Fungi perpustakaan salah satunya merupakan tempat rekreasi bagi masyarakat. perpustakaan dituntut berperan aktif, inovatif dan kreatif untuk membuat para pengunjung yang datang dapat merasa senang dan puas. Tata letak ruang perlu diperhatikan guna meningkatkan peran perpustakaan sebagi tempat rekreasi dan wahana pendidikan bagi masyarakat luas. Untuk menjadikan perpustakaan sebagai tempat rekreasi dan wahana pendidikan bagi pengunjung/masyarakat yang datang perlu adannya inovasi yang dilakukan berupa kegiatan atau layanan yang dibuat oleh pengelola perpustakaan. Tujuan penelitian ini untuk mengetahui inovasi kegiatan masa kini yang dilakukan perpustakaan kafe literacy coffee. Penelitian ini bertempat di perpustakaan kafe literacy coffee. Penelitian ini menggunakan metode kualitatif dengan pendekatan deskriptif. Teknik pengumpulan data dilakukan dengan cara observasi, wawancara, dan dokumentasi. reduksi data, penyajian data dan kesimpulan/verifikasi data merupakan analisis data dari penelitian ini. Hasil dari Penelitian ini adalah menunjukkan pengelola perpustakaan kafe literacy coffee mengembangkan kegiatan-kegiatan yang inovatif kepada pengunjung/masyarakat yang datang. Berbagai inovasi kegiatan yang dilakukan di perpustakaan kafe literacy coffee seperti diskusi umum, diskusi politik, bedah buku, bedah film, dan kelas film. Penelitian ini diharapkan menjadi acuan bagi perpustakaan kafe lainnya untuk mengembangkan atau meningkatkan kegiatan yang inovatif agar pengunjung/masyarakat betah berkunjung ke literacy coffee.

Kata Kunci: Perpustakaan Kafe; Kegiatan Literacy Coffee ; Inovasi Perpustakaan Kafe.

\section{A. PENDAHULUAN}

Perpustakaan kafe merupakan tempat warung kopi yang dikombinasikan dengan perpustakaan. Kombinasi antara warung kopi dan perpustakaan untuk menarik para pengunjung yang datang ke perpustakaan kafe. Perpustakaan kafe adalah suatu tempat yang telah didesain penuh dengan kenyamanan dan bisa dibuat tempat rekreasi oleh masyarakat yang tidak di jumpai pada perpustakaan konvensional (Puspitasari, 2017). Fungsi perpustakaan sebagai agen perubahan yang menjadikan perpustakaan salah satu pusat informasi (Ghofilah \& Rohman, 2021). Untuk menarik para 
pengunjung pengelola harus mendesain ruangan koleksi buku yang menarik, selain itu menyediakan kegiatan-kegiatan yang inovatif. Tujuan dibuatnya perpustakaan kafe untuk memberikan nilai lebih kepada perpustakaan dan memberikan tempat kenyamanan kepada pengunjung yang datang agar tidak merasa bosan ke perpustakaan. Pepustakaan Kafe bukan hanya tempat nongkrong makan dan minum tetapi juga sebagai tempat anak muda belajar secara mandiri maupun berkelompok (Karjodihardjo \& Honggowidjaja, 2015). Suasana kafe dapat didesain dengan suasana artistik dan menarik untuk mampu mengubah mood pengunjung merasa tenang dan nyaman. Suasana yang seperti ini akan membuat para pengunjung merasa betah berlama-lama sambil membaca buku yang telah disediakan. Konsep perpustakaan rekreatif bukan dianggap sabagai tempat membaca atau peminjaman koleksi saja, namun dapat juga sebagai tempat hiburan bersama teman maupun keluarga (Fatmawati, 2011).

Inovasi kegiatan perpustakaan kafe merupakan langkah yang harus diambil oleh pengelola perpustakaan kafe untuk memajukan minat baca pengunjung/masyarakat. Untuk meningkatkan minat baca dari pengunjung/masyarakat perlu dilakukan inovasi terhadap perpustakaan (Benawi, 2012). Perpustakaan yang berinovatif dapat dilakukan dengan ideode yang terkini, dengan kombinasi layanan dan teknologi (Fatmawati, 2016). Untuk menciptakan kegiatan-kegiatan yang inovatif harus ada upaya yang dapat dilakukan perpustakaan kafe. Kegiatan inovatif tersebut seperti berdiskusi, praktik memasak, praktik membuat kopi, pelatihan menulis, diskusi buku, cerdas cermat, dan sebagainya. Dengan adanya inovasi kegiatan perpustakaan kafe dapat mendorong minat maca, kemampuan, keterampilan, wawasan dan pengetahuan pengunjung/masyarakat. Perpustakaan harus memberikan informasi yang up to date kepada masyarakat, karena perpustakaan merupakan pusat sumber informasi (Mustar, 2021). Keberhasilan perpustakaan dalam memberikan layanan identik dengan upaya dan kemampuan perpustakaan menyediakan sumbersumber informasi yang dibutuhkan oleh pemakainya (Rejeki, 2020). Hal ini menjadikan kafe memiliki fungsi sebagai pusat informasi untuk menumbuhkan peningkatan minat baca (Lasa, 2009). Perpustakaan dengan konsep kafe akan memperoleh banyak manfaat, yaitu akan membuat masyarakat yang datang berkunjung ke perpustakaan yang akan dapat meningkatkan minat baca masyarakat sehingga dapat mencerdaskan masyarakat, menyediakan fasilitas yang nyaman sehingga mengubah pandangan masyarakat bahwa perpustakaan merupakan tempat yang menyenangkan untuk dikunjunjungi, sumber informasi. (Puspitasari, 2017). 
Literacy coffee merupakan perpaduan penggabungan konsep masa kini antara perpustakaan dan kedai kopi, serta menghadirkan berbagai kegiatan yang inovatif setiap minggunya. Kegiatan inovatif yang dapat menarik perhatian pengunjung yang datang ke literacy coffee tersebut seperti diskusi, bedah buku, diskusi politik, pemutaran film, dan kelas menulis. Kegiatan tersebut dilakukan literacy coffee agar pengunjung yang datang tidak akan merasa jenuh dan bosan. Jumlah pengunjung perpustakaan kafe literacy coffee semakin lama semakin meningkat karena eksistensi pengelola dalam mengembangkan literacy coffee semakin baik. Selain itu perpustakaan kafe literacy coffee dapat dijadikan tempat atau sarana edukatif bagi pengunjung/masyarakatnya. Upaya inovasi penggabungan perpustakaan dan kafe di masyarakat luas akan dapat membangun citra perpustakaan yang semakin eksis pada masyarakat dengan perbaduan edukasi dan rekreasi perpustakaan (Safiyya, 2014).

Penelitian ini menggunakan metode kualitatif dengan pendekatan deskriptif. Penelitian kualitatif adalah jenis penelitian di mana peneliti sangat tergantung terhadap informasi dari objek/partisipan pada ruang lingkup yang luas, pertanyaan yang bersifat umum, pengumpulan data yang sebagian besar terdiri atas kata-kata/teks dari partisipan, menjelaskan dan melakukan analisa terhadap katakata dan melakukan penelitian secara subyektif (Creswell, 2008). Metode pendekatan kualitatif deskriptif ialah suatu metode pengolahan data yang dilakukan dengan menganalisis faktor-faktor yang berkaitan dengan objek penelitian dengan penyajian data secara lebih mendalam terhadap suatu objek penelitian, (Prabowo, A., 2013). Penelitian ini bertempat di perpustakaan kafe literacy coffee di jalan jati II Teladan timur kecamatan medan kota. Observasi, wawancara dan dokumentasi sebagai pengumpulan data pada penelitian ini. Pengumpulan data merupakan usaha membatasi penelitian, mengumpulkan informasi melalui observasi dan wawancara baik terstruktur maupun tidak, serta usaha merancang untuk merekam dan mencatat informasi (Creswell, 2009). Observasi merupakan kegiatan tahap awal proses penelitian melalui pengamatan langsung ke lapangan dengan melihat gejala-gejala yang sedang terjadi. Wawancara merupakan proses pengumpulan data untuk mendapatkan informasi dari sumber yang terpercaya secara langsung maupun tidak langsung. Dokumentasi merupakan pengumpulan data yang berupa dokumen atau catatan penting terkait penelitian sebagai sumber data yang digunakan untuk menganalisis. Analisis data dilakukan peneliti dengan beberapa tahapan, yaitu reduksi data, penyajian data dan kesimpulan/verifikasi data (Miles and Huberman, 2007). Reduksi data pada penelitian ini untuk mempermudah peneliti meringkas dan mengklasifikasikan data sesuai fokus yang telah 
dikumpulkan melalui observasi, wawancara dan dokumentasi. Pada proses penyajian data, peneliti menyajikan paparan secara naratif secara jelas. Tahap terakhir peneliti melakukan verifikasi data dengan membuat kesimpulan berdasarkan data yang telah diperoleh di lapangan. Kemudian diverifikasi kebenaran yang telah dikumpulkan saat penelitian berlangsung.

\section{B. HASIL DAN PEMBAHASAN}

Perpustakaan dapat dijadikan alternatif perubahan yang inovatif, khususnya pada perpustakaan kafe yang dapat dijadikan alternatif yang inovatif sebagai tempat rekreasi/wisata pendidikan. Fungi perpustakaan salah satunya merupakan tempat rekreasi bagi masyarakat. Semua kalangan masyarakat dari anak-anak sampai orang dewasa berhak memanfaatkan layanan perpustakaan. Seperti menggunakan fasilitas koleksi yang ada, memanfaatkan ruangan bermain anak, berdiskusi, mencari informasi menggunakan layanan internet dan lain-lain. Pada Undang-Undang Nomor 43 Tahun 2007 pasal 3 disebutkan bahwa perpustakaan berfungsi sebagai wahana pendidikan, penelitian, pelestarian, informasi, dan rekreasi untuk meningkatkan kecerdaskan dan keberdayaan bangsa (Indonesia, 2007). Jadi, dapat diartikan perpustakaan sebagai tempat rekreasi juga wahana pendidikan bagi masyarakat yang sedang mempunyai waktu aktifitas yang panjang. Paradigma baru tentang fungsi dari rekreasi merupakan tempat yang nyaman juga dapat menyajikan informasi yang sifatnya menyenangkan, selain itu sebagai tempat menghasilkan karya baru yang berpijak dari karya orang lain yang telah dipublikasikan (Suwarno, 2016). Orang yang berkunjung ke perpustakaan dapat memperoleh hasil yang sama dengan orang yang melakukan kunjungan wisata, dikarenakan sama-sama mendapatkan hiburan dan pembelajaran (Kohar, 2011). Untuk menjadikan perpustakaan seperti tempat rekreasi bagi para pengunjung sangatlah tidak gampang dan perlu keberanian tersendiri bagi pengelola yang benar-benar membentuk perpustakaan untuk masyarakat. Disini perpustakaan akan dituntut harus berperan aktif, inovatif dan kreatif untuk membuat para pengunjung yang datang dapat merasa senang dan puas. Pembenahan dan perbaikan tata letak ruang perlu diperhatikan guna meningkatkan peran perpustakaan sebagi tempat rekreasi dan wahana pendidikan bagi masyarakat luas. Untuk menjadikan perpustakaan sebagai tempat rekreasi dan wahana pendidikan bagi pengunjung/masyarakat yang datang perlu adannya inovasi yang dilakukan berupa kegiatan atau layanan yang dibuat oleh pengelola perpustakaan.

Perpustakaan kafe literacy coffee memiliki berbagai kegiatan yang inovatif kepada pengunjung/masyarakat yang datang ke perpustakaan kafe 
literacy coffee. Kegiatan inovatif yang dilakukan di perpustakaan kafe literacy coffee ada diskusi, bedah buku, bedah film, nonton bareng, kelas produksi film

\section{Diskusi}

Untuk meningkatkan minat baca para pengunjung ke perpustakaan kafe literacy coffee dapat dilakukan dengan berbagai kegiatan, salah satunya melalui diskusi. Diskusi merupakan interaksi komunikasi antara seseorang maupun kelompok untuk mendapatkan pengetahuan dan wawasan yang luas yang bertujuan memberikan pemahaman mengenai suatu topik permasalahan. Literacy coffee juga melakukan upaya meningkatkan minat baca dengan membuat forum diskusi.

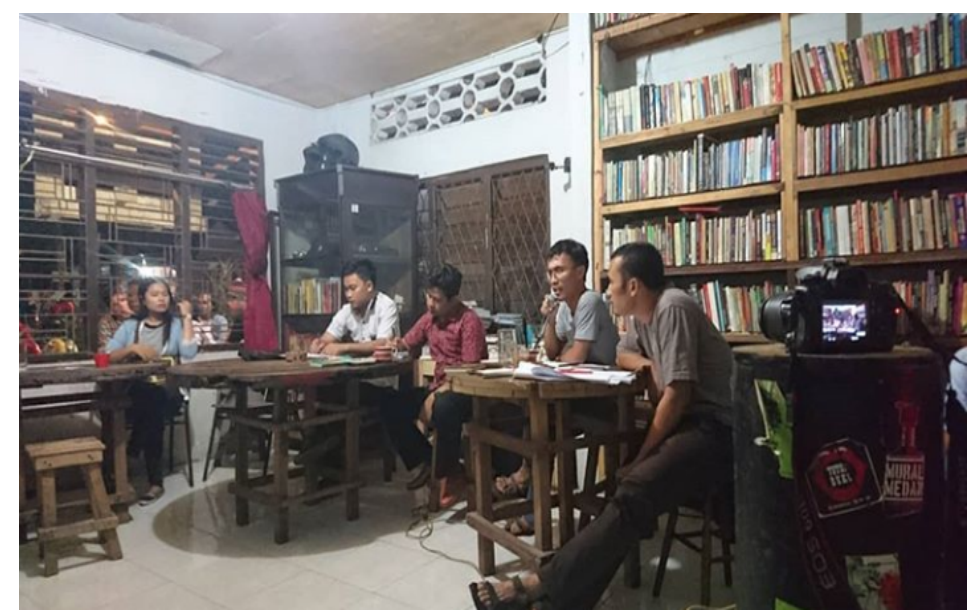

Gambar 1 Kegiatan diskusi di Literacy Coffee

Sumber: Literacy Coffee

Ada topik yang akan dibahas pada saat kegiatan diskusi berlangsung oleh peserta didalamnya. Literacy coffee menyediakan topik diskusi yang sudah ditentukan dan biasanya topik yang dibahas adalah kondisi yang sedang update dikalangan masyarakat. Beberapa tema diskusi yang dibahas bersama para pakar tertera di tabel ini. 
Tabel 1 Tema diskusi literacy coffee

\begin{tabular}{|c|c|}
\hline Judul & Pembicara \\
\hline $\begin{array}{l}\text { "Harapan Masyarakat Sumatera Utara } \\
\text { Tahun 2018-2023 }\end{array}$ & $\begin{array}{l}\text { Agus Andreas,Dadang Darmawan, } \\
\text { Abyadi Siregar }\end{array}$ \\
\hline $\begin{array}{l}\text { "Memperingati hari Pahlawan Di } \\
\text { Sekitar Revolusi" }\end{array}$ & $\begin{array}{l}\text { Tengku A. Dipantara, Dian Purba, } \\
\text { Fajar Anugrah }\end{array}$ \\
\hline $\begin{array}{l}\text { "Sastra dan Kesadaran Kritis } \\
\text { Berbangsa" }\end{array}$ & Yudhistira ANM Massardi \\
\hline $\begin{array}{l}\text { "Bincang-bincang karya Renjaya } \\
\text { Siahaan" }\end{array}$ & Ahmad Arief \\
\hline $\begin{array}{l}\text { "Bincang-Bincang Bersama Saut } \\
\text { Situmorang" }\end{array}$ & Saut situmorang \\
\hline $\begin{array}{l}\text { "Membatik Eksperimen, Panggung } \\
\text { Perempuan..." }\end{array}$ & Perempuan hari ini \\
\hline "Peristiwa 1998 di Medan" & Dian Purba dan Juhendri Chaniago \\
\hline $\begin{array}{l}\text { "Literasi dan Perananya Sebagai } \\
\text { Propoganda Lingkungan Dewasa Ini } \\
\text { Bersama Solidaritas Mahasiswa } \\
\text { Peduli Lingkungan, Nonton Bareng } \\
\text { Film "Asimetris" }\end{array}$ & $\begin{array}{l}\text { Tedy Wahyudi Pasaribu, Mapala } \\
\text { UMA dan Acoustican }\end{array}$ \\
\hline $\begin{array}{l}\text { "Cakap-cakap Ikwal UU Terorisme" } \\
\text { "Demokrasi Jerman dan Indonesia" }\end{array}$ & $\begin{array}{l}\text { Gindo Nadapdap, Shohibul Ansor } \\
\text { Siregar Quadi Azam } \\
\text { Dadang Darmawan, Max Mantell } \\
\text { Moderator Sisil Nadeak }\end{array}$ \\
\hline
\end{tabular}

\section{Bedah Buku}

Bedah buku merupakan acara atau kegiatan untuk mengetahui isi dari buku tersebut secara ringkas serta memberikan saran terkait dengan kekurangan dan kelebihan yang dimiliki buku tersebut. Ada banyak manfaat 
yang dapat diambil dari kegiatan yang dilakukan seperti mendapatkan pengetahuan dan wawasan yang luas yang berkenaan dengan kehidupan sehari-hari serta dari berbagai perspektif lainnya. Keikutsertaan pengunjung dalam menyimak bedah buku dari para pakar akan dapat mengambil pembelajaran yang baik, sehingga dalam membedah buku dapat mengambil pembelajaran dari sebuah buku.

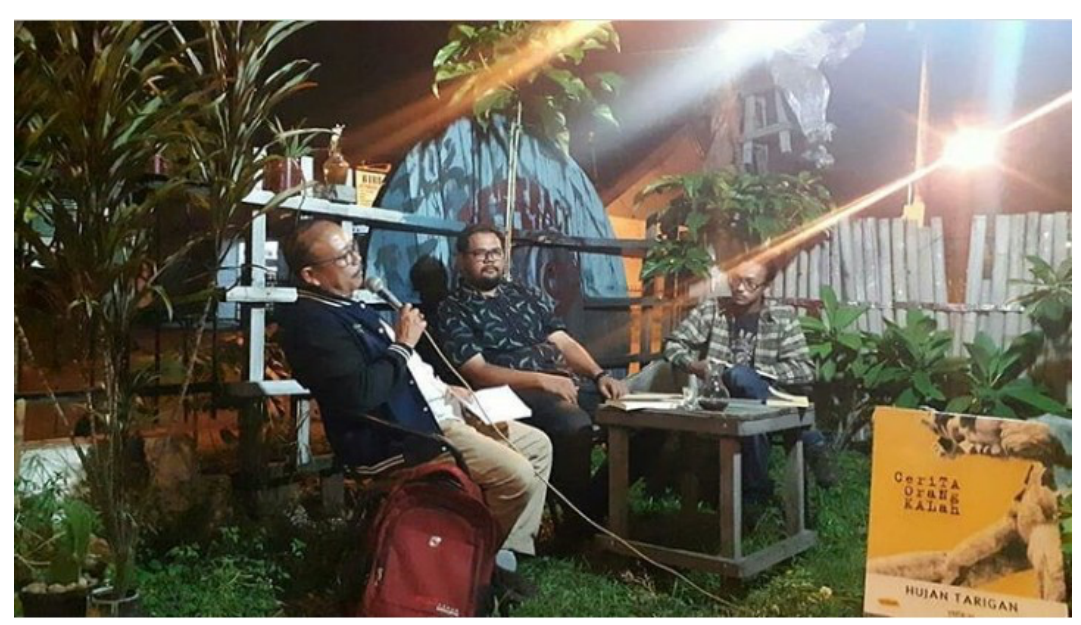

Gambar 2 Kegiatan Bedah Buku di Literacy Coffee Sumber: Literacy Coffee

Literacy coffee melakukan kegiatan bedah buku sekali dalam seminggu. Kegiatan ini terbuka untuk umum, dalam arti siapapun bisa menjadi peserta dalam bedah buku tersebut. Dalam kegiatan ini, pihak literacy coffee bukan pihak yang mengisi acara melainkan sebagai pihak fasilitator. Dalam arti pihak literacy coffee hanya memfasilitasi berjalannya suatu acara bukan sebagai pihak yang menjalankan acara. Pemateri dalam bedah buku biasanya dari kalangan pakar, akademisi, sastrawan serta pegiat seni lainnya. Pihak yang menjadi pengisi acara setiap minggunya selalu berganti ganti. dan biasanya pemateri menawarkan diri atau diundang oleh pihak literacy coffee itu sendiri. Beberapa tema kegiatan bedah buku di literacy coffee dapat dilihat pada tabel berikut.

Tabel 2. Tema kegiatan bedah buku di literacy coffee 


\begin{tabular}{l|l}
\hline "Genealogi Kapitalisme" & Lewis Siahaan \\
"Merahnya Merah" & Andreas Hutauruk \\
"Perpustakaan Kelamin" & Hartina Manurung \\
"Widji Thukul" & Clinton Naga Negara Sinaga \\
"Dosa-dosa Politik Orde Baru" & Kristina Ginting \\
"Catatan Seorang Demonstran" & M. Arief Rusyidi \\
"Indonesia Tidak Hadir di Bumi Manusia" & Dian Purba, Roy Martin Simamora \\
"Ekologi dan Anarkisme" & Amanda Hidayat Lubis. \\
"Pendidikan Kaum Tertindas & Danny Hutabarat \\
"Indonesia Tidak Hadir di Bumi Manusia" & Dian Purba, Roy Martin Simamora \\
\hline
\end{tabular}

\section{Bedah film}

Bedah film merupakan kegiatan menonton sebuah film secara bersama sama dan melakukan diskusi setelah menonton film yang berkaitan dengan kehidupan sehari hari. Ada banyak manfaat yang dapat diambil dari bedah film ini adalah untuk penonton dapat memahami bahwa dalam sebuah film tersimpan banyak pesan dan pengetahuan yang bisa dijadikan pelajaran hidup, baik itu berkaitan dengan kehidupan sosial politik, ekonomi, budaya dan lain-lain.

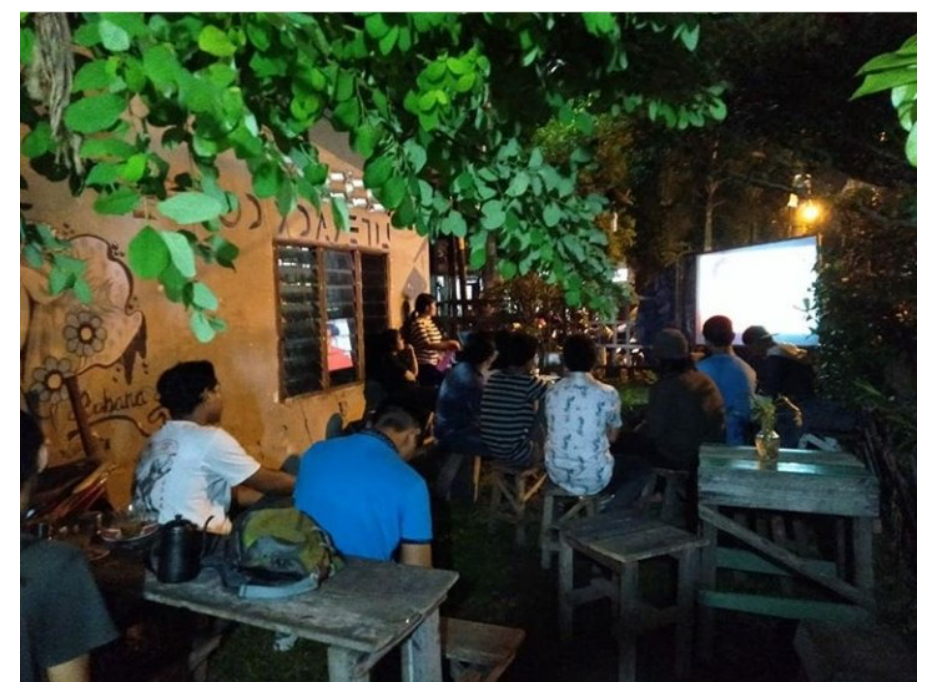

Gambar 3: Kegiatan bedah Film di Literacy Coffee Sumber: Literacy Coffee

Literacy coffee melakukan kegiatan diskusi film sekali dalam seminggu. Kegiatan ini terbuka untuk umum dalam arti siapapun juga bisa menjadi peserta dalam diskusi tersebut. Pihak yang menjadi pengisi acara setiap minggunya selalu berganti-ganti, tergantung pihak literacy coffee sendiri apakah ingin mengundang atau menerima tawaran pihak yang 
berkenan menjadi pengisi diacara bedah film di literacy coffee. Beberapa tema kegiatan bedah film di literacy coffee dapat dilihat pada tabel berikut.

Tabel 3. Tema kegiatan Bedah Film di literacy coffee

\begin{tabular}{l|l}
\hline \multicolumn{1}{c|}{ Judul } & \multicolumn{1}{c}{ Pembicara } \\
\hline "Muhammad The Messenger Of God" & Degil Zine. \\
"Rebel In The Rye" & Degil Zine dan Literacy. \\
"Rakut Sitelu" & Andi Hutagalung. \\
"Before The Flood" dan diskusi". & Degil Zine. \\
"Rembah Pribumi" sutradara Gracia Tobing" & Abram Cristopher Sinaga (produser film). \\
"The True Cost" & Eda Citra, Eka Dalanta, Acoustic: Funky Jaya, Adrian \\
& Timothy, Seloka Beruk, Bastian Siregar dan Genk, Puisi: \\
& Robby Sirait, Jhon fawer Siahaan \\
"Ini Scene kami juga!" & Rei Tarigan \\
"Ibu" & Patar Simatupang \\
"Experimentalia Jalan Menuju Sorga" & Henry Norman. \\
"The Protest suara dari jalan" & Diana Saragih. \\
& \\
\hline
\end{tabular}

\section{Nonton Bareng (Nobar)}

Kegiatan berikut yang dilakukan literacy coffee adalah Nonton bareng yang sering didengar dengan sebutan nobar. Nobar ini merupakan kegiatan bersama-sama menyaksikan film atau video yang dilakukan literacy coffee. Kegiatan nobar ini dilaksanakan sekali dalam tiap minggunya. Kegiatan ini bertujuan untuk menjaga persaudaraan antara pengunjung, pengelola dan warga masyarakat sekitar, selain itu untuk meningkatkan literasi informasi pengunjung/masyarakat. 


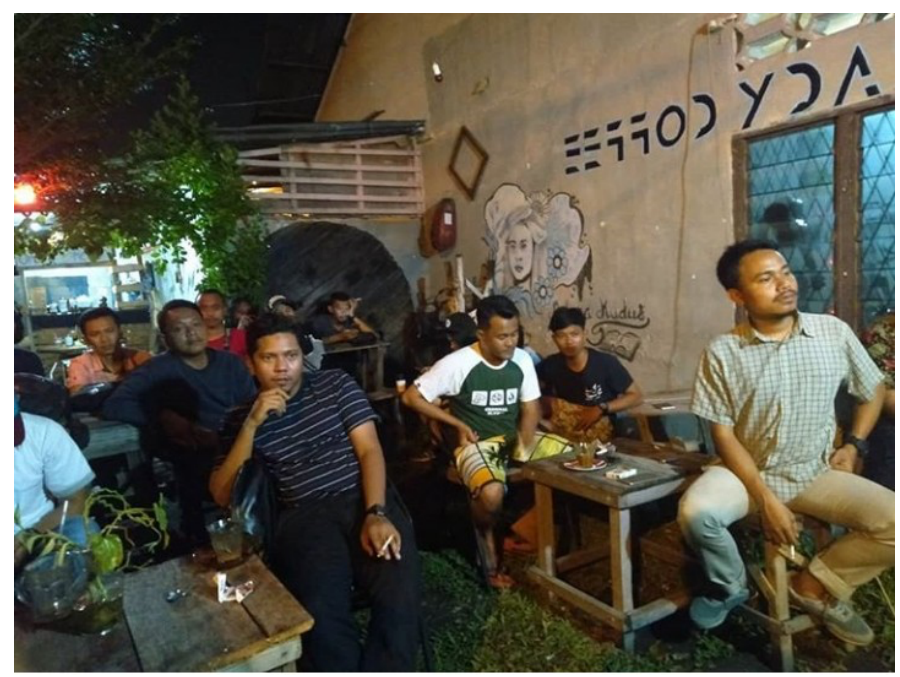

Gambar 4 Nonton bareng para pengunjung Sumber: Literacy Coffee

Kegiatan nonton bareng ini merupakan kegiatan aktif yang dilakukan perpustakaan kafe literacy coffee kepada pengunjung yang hendak menikmati kopi secara bersama-sama sambil menonton film dengan para pengunjung lainnya. Film maupun video yang ditayangkan dalam nonton bareng berupa film/video yang mempunyai nilai morak yang dikemas secara menarik.

\section{Kelas Produksi Film}

Kelas produksi film merupakan salah satu kegiatan yang dilaksanakan pada perpustakaan kafe literacy coffee. Kegiatan yang dilakukan pada kelas produksi film ini untuk memberikan kemampuan seseorang peserta kelas dalam berkarya memproduksi/menghasilkan film yang baik. 


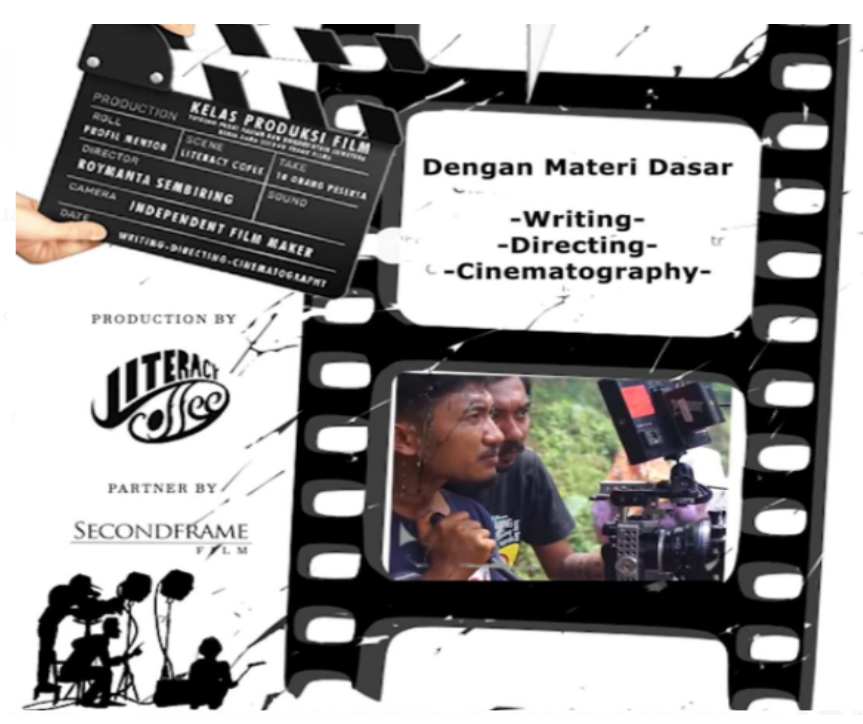

Gambar 5 Praktik pembuatan film Sumber: Literacy Coffee

Kegiatan ini bertujuan untuk mengenalkan seseorang yang menekuni perfilman terkait writing, directing, cinematography. Kegiatan kelas ini dibuka untuk 10 orang peserta kelas dengan 8 kali pertemuan. Pemateri merupakan filmaker yang bernama Roymanta Sembiring. Kegiatan ini bekerjasama dengan secondframe film.

\section{KESIMPULAN}

Perpustakaan kafe merupakan perpustakaan yang didesain dengan warung kopi dan buku. Perpustakaan kafe yang baik ketika pengelola perpustakaan kafe perperan aktif membuat kegiatan-kegiatan yang inovatif, karena langsung menyentuh langsung ke psikologis para pengunjung dan menciptakan suasana nyaman. Perpustakaan kafe literacy coffee memiliki berbagai kegiatan. Kegiatan inovatif yang dilakukan di perpustakaan kafe literacy coffee ada diskusi, bedah buku, bedah film, nonton bareng, kelas produksi film. Kegiatan ini dilakukan untuk dapat menarik para pengunjung/masyarakat yang datang ke literacy coffee. Dengan berbagai kegiatan aktif yang dilakukan perpustakaan kafe literacy coffee dapat dijadikan alternative bagi perpustakaan kafe literacy coffee sebagai daya tarik tempat rekreasi dan wahana edukasi pembelajaran yang menyenangkan untuk dikunjungi oleh masyarakat agar tidak merasa bosan.

\section{DAFTAR RUJUKAN}


Benawi, I. (2012). Perpustakaan Kafe dan Warkop adalah Sebuah

Perpustakaan Inovasi Masa Kini. Jurnal Iqra Okt, 06(02), 1-11.

http://repository.uinsu.ac.id/764/1/vol.06no.02 \%282\%29.pdf

Creswell, J. W. (2008). Educational Research Planning, Conducting, and

Evaluating Qualitative and Qualitative Research. Pustaka Pelajar.

Creswell, J. W. (2009). Research Design Pendekatan Penelitian Kualitatif, Kuantitatif, dan Mixed. Pustaka Pelajar.

Fatmawati, E. (2011). The Art of Library. Universitas Diponegoro.

Fatmawati, E. (2016). Merajut Inovasi Pustakawan Perguruan Tinggi Untuk Mewujudkan SDM Perpustakaan Berkualitas. Jurnal Pustakaloka, 8(2), 259-270.

Ghofilah, P. N. N. ;Sukaesih;Evi N. R., \& Rohman, A. S. (2021). Inovasi Pelayanan Dinas Kearsipan dan Perpustakaan. Tik Ilmeu : Jurnal Ilmu Perpustakaan Dan Informasi, vol.5; No.

https://doi.org/10.29240/tik.v5i1.2121

Indonesia. (2007). Undang-Undang No. 43 Tahun 2007 Tentang Perpustakaan.

Karjodihardjo, Y. H., \& Honggowidjaja, S. P. (2015). Perancangan Interior Library Cafe di Surabaya. Intra, 3(2), 256-267.

http://publication.petra.ac.id/index.php/desain-interior/article/view/3590

Kohar, A. (2011). Pengembangan Fungsi Rekreasi Di Perpustakaan. http://www.pdii.lipi.go.id

Lasa, H. (2009). Peran Perpustakaan Dan Penulis Dalam Peningkatan Minat Baca Masyarakat. No.2, 13-14.

Miles and Huberman. (2007). Qualitative Data Analysis. London : SAGE Publication.

Mustar, M. (2021). Inovasi Perpustakaan dalam Mendukung Program ELearning di masa Pandemi Covid-19. Daluang Journal of Library and Information ..., 01(01), 42-51. https://doi.org/10.21580/daluang.v1i1.2021.7975

Prabowo, A., \& H. (2013). Analisis Pemanfaatan Buku Elektronik ( E-Book ) Oleh Pemustaka Di Perpustakaan Sma Negeri 1 Semarang. Jurnal Ilmu Perpustakaan, 2(2), 1-9.

Puspitasari, D. (2017). Library Cafe : Suatu Alternatif dalam Meningkatkan 
Minat Baca Masyarakat. 6(2), 79-86.

Rejeki, S. (2020). Inovasi Dalam Pengembangan Koleksi. Buletin

Perpustakaan Univerisitas Islam Indonesia, 3(1), 131-145.

https://journal.uii.ac.id/Buletin-Perpustakaan/article/view/15199

Safiyya, G. R. N. K. (2014). Penerapan Konsep Library Cafe Di The Reading

Room Jakarta. Jurnal Kajian Informasi \& Perpustakaan, Vol.2/No.2, hlm 121-128.

Suwarno, W. (2016). Ilmu Perpustakaan \& Kode Etik Pustakawan.

Yogyakarta: ARRUZ Media. 